\title{
Effect of obesity on postoperative outcomes in patients with left ventricular assist device
}

\author{
Orhan Gokalp ${ }^{1} \cdot$ Hasan Iner ${ }^{2}$ (D) Yuksel Besir ${ }^{1} \cdot$ Nihan Karakas Yesilkaya $^{3} \cdot$ Gamze Gokalp $^{4} \cdot$ Kazim Ergunes $^{5}$. \\ Sahin Iscan ${ }^{5}$
}

Received: 11 February 2018 / Accepted: 15 March 2018 / Published online: 7 April 2018

(c) The Japanese Society for Artificial Organs 2018

We congratulate Volkovicher and colleagues for their successful study [1]. We found the main outcome of their study very interesting that obesity is not a risk factor for mortality in patients with left ventricular assist device (LVAD). Even as the authors have briefly stated in the discussion section, obesity does not seem to be a risk factor for mortality in similar studies with LVAD patients [2,3]. However, this does not exactly coincide with our current knowledge of the general outcome of the cardiac surgery. Because obesity is described as a risk factor for mortality in many studies involving cardiac surgery without any LVAD patient [4-6]. In many of these studies, apart from mortality rate, the negative effects of obesity on many parameters such as re-hospitalization, the incidence of postoperative surgical infection, prolonged duration of stay in the intensive care unit, prolonged ventilation, and the incidence of postoperative renal failure have been reported. In the authors' study, obesity does not seem to be a problem in terms of mortality and many of these parameters. But, the remarkable expression in these studies we have exemplified is "extreme obesity". So, the main issue mentioned in these studies is

This comment refers to the article available at: https://doi. org/10.1007/s10047-017-1013-2.

Hasan Iner

hasan_iner@hotmail.com

1 Department of Cardiovascular Surgery, Faculty of Medicine, Katip Celebi University, Izmir, Turkey

2 Department of Cardiovascular Surgery, Adiyaman Education and Research Hospital, Adiyaman, Turkey

3 Department of Cardiovascular Surgery, Faculty of Medicine, Ankara University, Ankara, Turkey

4 Department of Paediatrics Emergency, Tepecik Education and Research Hospital, Izmir, Turkey

5 Department of Cardiovascular Surgery, Izmir Ataturk Education and Research Hospital, Izmir, Turkey extremely high body mass index (BMI). In fact, in the authors' study, mortality rate is also seen to increase somewhat as the $\mathrm{BMI}$ increases. Is not there too much generalization in this context while reporting that obesity has no effect on mortality? Would not it be more appropriate to emphasize that the situation is different in obese patients with morbid obesity? We believe that learning about the authors' ideas on this subject will add value to their study.

\section{Compliance with ethical standards}

Conflict of interest The authors declare that they have no conflict of interest.

\section{References}

1. Volkovicher N, Kurihara C, Critsinelis A, Kawabori M, Sugiura T, Manon M 2nd, Civitello AB, Morgan JA. Effect of obesity on outcomes in patients undergoing implantation of continuous-flow left ventricular assist devices. J Artif Organs. https://doi.org/10.1007/ s10047-017-1013-2.

2. Go PH, Nemeh HW, Borgi J, Paone G, Morgan JA. Effect of body mass index on outcomes in left ventricular assist device recipients. J Card Surg. 2016;31:242-7.

3. Brewer JR, Lanfear DE, Sai-Sudhakar CB, Sundareswaran KS, Ravi Y, Farrar DJ, Slaughter MS. Extremes of body mass index do not impact mid-term survival after continuous-flow left ventricular assist device implantation. J Heart Lung Transpl. 2012;31:167-72.

4. Protopapas AD. Does body mass index affect mortality in coronary surgery? Open Cardiovasc Med J 2016;10:240-5. https://doi. org/10.2174/1874192401610010240 (eCollection 2016).

5. Syrakas CA, Neumaier-Prauser P, Angelis I, Kiask T, Kemkes BM, Gansera B. Is extreme obesity a risk factor for increased in-hospital mortality and postoperative morbidity after cardiac surgery? Results of 2251 obese patients with BMI of 30 to 50 . Thorac Cardiovasc Surg. 2007;55:491-3.

6. Wigfield CH, Lindsey JD, Muñoz A, Chopra PS, Edwards NM, Love RB. Is extreme obesity a risk factor for cardiac surgery? An analysis of patients with a BMI $>$ or $=40$. Eur J Cardiothorac Surg. 2006;29:434-40. 